TITLE:

\title{
Fundamental equation based on pole allocation for interstory seismic isolation of buildings
}

\author{
AUTHOR(S): \\ Ikeda, Yoshiki
}

\section{CITATION:}

I keda, Yoshiki. Fundamental equation based on pole allocation for interstory seismic isolation of buildings. Structural Control and Health Monitoring 2021, 28(3): e2687.

\section{ISSUE DATE:}

2021-03

URL:

http://hdl.handle.net/2433/267470

\section{RIGHT:}

This is the peer reviewed version of the following article: [lkeda, Y. Fundamental equation based on pole allocation for interstory seismic isolation of buildings. Struct Control Health Monit. 2021; 28:e2687.], which has been published in final form at https://doi.org/10.1002/stc.2687. This article may be used for non-commercial purposes in accordance with Wiley Terms and Conditions for Use of Self-Archived Versions. This article may not be enhanced, enriched or otherwise transformed into a derivative work, without express permission from Wiley or by statutory rights under applicable legislation. Copyright notices must not be removed, obscured or modified. The article must be linked to Wiley's version of record on Wiley Online Library and any embedding, framing or otherwise making available the article or pages thereof by third parties from platforms, services and websites other tha.. 
Fundamental Equation Based on Pole Allocation for Inter-story Seismic Isolation of Buildings

\author{
Yoshiki IKEDA
}

Division of Earthquake Hazards, Disaster Prevention Research Institute, Kyoto University

Gokasho, Uji, Kyoto 611-0011, Japan

E-mail: ikeda.yoshiki.6r@kyoto-u.ac.jp

\begin{abstract}
SUMMARY
An inverse problem is formulated based on the pole allocation method in control theory, for a building with an inter-story seismic isolation system. The structural system is simplified as a three-degree-of-freedom lumped-mass shear model. The natural frequencies and the corresponding damping ratios in the three vibration modes are set as the initial control target. To achieve this target, the introduced solution provides the natural frequencies of the lower substructure, upper substructure, and isolator with damper capacity. It simultaneously provides the mass distribution for the three lumped masses. The closed-form expression clarifies how the isolator's natural frequency and damper's capacity are related to the dominant natural frequencies of both the substructures and to the target modal damping ratios. The mathematical expression explains the tradeoff relationship between the damping ratios of the lower and upper substructures. Furthermore, the solution is applied to directly estimate the damping effect by a tuned mass damper. The inverse problem approach is effective for understanding the general and essential dynamic characteristics of inter-story seismic isolation.
\end{abstract}

\title{
KEY WORDS
}

inter-story seismic isolation, 3-DOF model, pole allocation, characteristic equation, closed solution, TMD

\section{INTRODUCTION}

In this study, the fundamental dynamic characteristics of a building with an inter-story seismic isolation system are analyzed by applying the pole allocation method ${ }^{1}$ to a three-degree-of-freedom (3-DOF) lumped-mass shear model. It is well known that the inter-story isolation system displays a moderately complex dynamic characteristic because of the modal coupling behavior between the lower and upper substructures ${ }^{2,3}$. The new solution, which is introduced in a closed form, clarifies how the isolator's natural frequency and damper's capacity are related to the dominant natural frequencies of both the substructures 
and to the control target. In this study, the control target refers to the natural frequencies and the corresponding damping ratios in the three vibration modes. The analytical approach can potentially address to discuss inter-story seismic isolation and tuned mass damper (TMD) with the same mathematical equation.

The number of inter-story seismic isolation systems used in practical applications is increasing in response to the growing interest in the redevelopment of large modern cities and seismic retrofitting of existing buildings. Architectural flexibility requirements have extended the limits of traditional base isolation technology to search for new structural configurations. Research and development performed on inter-story seismic isolation for buildings in Japan has been published since the late $1990 \mathrm{~s}^{4-11}$. Several early references investigated how the location of the inter-story isolation and the recommended capabilities of inter-story isolators and dampers influence seismic structural response ${ }^{12-15}$. The research conclusions describe various dynamic characteristics of buildings with inter-story seismic isolation. The key knowledge from these indicates a specific physical phenomenon that can be observed only in the inter-story isolation: The seismic response of the upper substructure may be amplified by the modal coupling behavior between the lower and upper substructures, and the seismic response of the lower substructure may be suppressed by the TMD effect of the upper substructures $^{2,3,12,16}$. In structural design, the tradeoff relationship between the amplification and reduction of seismic response creates a pair of physical phenomena. It requires deep consideration in conjunction with this concept. System identification ${ }^{17}$ and shake table real-time hybrid simulation technique ${ }^{18}$ are applied to identify the complicated interaction between the lower and upper substructures under an earthquake excitation.

To date, studies on inter-story seismic isolation have been performed through two typical types of analyses: 1) consider a 2-DOF lumped-mass shear model ${ }^{13}, 15,19-22$ as a simplified structural system and 2) consider a larger lumped-mass model with more degrees of freedom 6-8, 10, 12. The consideration of the 2-DOF model appears to be linked with a mathematical expression problem in that it is more or less difficult to handle a 3-DOF model in a closed form even under the linearity assumption. If the upper substructure is significantly stiffer than the lower substructure, it is apparently possible to study the inter-story seismic isolation with the 2-DOF model. The 2-DOF model is effective for understanding the fundamental dynamic characteristics of base seismic isolation for a low-rise building ${ }^{23}$. However, advanced research on inter-story seismic isolation requires a model with at least 3-DOF ${ }^{24-26}$ because the modal coupling between the lower and upper substructures has been identified. Meanwhile, parametric studies are effective for understanding the dynamic characteristics of a specific target building 6-8,10,12. The parametric approach has a limitation in its extraction of the general, essential, and scientific characteristics from the numerical results.

The simplified 3-DOF model has been utilized to discuss the modal coupling behavior between the substructures in a closed form ${ }^{25,26}$. The research clearly describes the following: (1) the natural frequency and damping ratio in the first mode of the overall structural system 
are very close to the natural frequency and damping ratio of the inter-story; (2) the first modal damping ratio, mainly of the inter-story, is significantly affected by the masses and natural frequencies of both the substructures; and (3) the ratios of the natural frequencies of the substructures to that of the inter-story categorize the modal coupling into three phenomenal regions: the second mode effective region, third mode effective region, and modal coupling region.

This paper presents research on inter-story seismic isolation from a novel perspective by applying the pole allocation method to the 3-DOF lumped-mass model because the method is clarified into an inverse problem. In addition, the mathematical solution is introduced in another closed form. Unlike previous research, modal damping ratios are discussed to consider the modal coupling and interaction with another closed solution from the perspective of structural passive control. Section 2 introduces the 3-DOF linear model to represent its modal properties as a control target. The solution based on the pole allocation clearly describes the dynamic properties of the inter-story isolator and the corresponding damper, and their influence on the natural frequencies and the damping ratios in the three vibration modes of an overall building. Furthermore, the solution is transformed as damping ratios in the 2-DOF TMD-structure model to directly understand the control effectiveness of the TMD. Section 3 verifies the introduced solution by using three ten-degree-of-freedom (10-DOF) lumped-mass shear models representing the modal coupling between the lower and upper substructures. The numerical examples clarify the fundamental dynamic characteristic of inter-story seismic isolation. The inverse problem approach provides a basic design method for inter-story seismic isolation of a building, particularly at the initial design stage. A summary and the conclusions are presented in the final section.

\section{FUNDAMENTAL EQUATION}

\subsection{State equation}

As shown in Figure 1, a 3-DOF lumped-mass shear model is considered to formulate a fundamental mathematical equation for the inter-story seismic isolation of building structures. An isolator and the corresponding damper are installed in parallel in the inter-story. The lower and upper substructures are modeled as single-DOF (S-DOF) undamped systems, because in many cases the original damping ratios in the substructures are smaller than those produced by the inter-story damper. In general, inter-story isolation significantly reduces seismic responses of the upper substructure, but not that much of the lower substructure. This means that the original damping ratio of the upper substructure itself is small because it is isolated, and the damping ratio of the lower substructure is also small because it is not isolated. For example, the high-rise building with inter-story seismic isolation utilizes viscous material shear walls for response control of the lower substructure ${ }^{10}$. Previous research indicated that the fundamental dynamic properties of seismic isolation can be investigated under the equivalent linearity assumption ${ }^{3,6,23-26}$. Here, the 3 -DOF model is also assumed to be a linear 
shear system. This assumption enables a convenient discussion of its dynamic characteristics in a closed form $23,25,26$. The lower and upper substructures are generally called substructure and superstructure, respectively ${ }^{24-26}$.

The pole allocation method ${ }^{1}$ in control theory is applied to the 3-DOF linear shear model for designing inter-story seismic isolation. The scalar equations of motion under an earthquake excitation can be introduced as

$$
\begin{gathered}
m_{U} \ddot{x}_{U}+k_{U}\left(x_{U}-x_{I}\right)=-m_{U} \ddot{y}_{0} \\
m_{I} \ddot{x}_{I}+c_{I}\left(\dot{x}_{I}-\dot{x}_{L}\right)-k_{U}\left(x_{U}-x_{I}\right)+k_{I}\left(x_{I}-x_{L}\right)=-m_{I} \ddot{y}_{0} \\
m_{L} \ddot{x}_{L}-c_{I}\left(\dot{x}_{I}-\dot{x}_{L}\right)-k_{I}\left(x_{I}-x_{L}\right)+k_{L} x_{L}=-m_{L} \ddot{y}_{0}
\end{gathered}
$$

where $m_{U}$ is the total mass of the upper substructure, $m_{L}$ is the total mass of the lower substructure, and $m_{I}$ is the mass of the floor immediately above the isolation inter-story. It may also be observed that the definition of $m_{I}$ is largely ideal. The ideal definition will become clear if one refers to Table 3 (the details of which are explained in Section 3.3), because the obtained $m_{I}$ seems to be larger than the floor mass above the isolation story. $k_{U}$ and $k_{L}$ are the shear stiffness values for the upper and lower substructures, respectively. $k_{I}$ is the shear stiffness of the isolator, and $c_{I}$ is the damping coefficient of the installed damper. $\ddot{y}_{0}$ is the ground acceleration input to the structural system. $x_{U}, x_{I}$, and $x_{L}$ are the displacements of the lumped masses relative to the base. $x_{U}$ and $x_{L}$ represent the displacements of the upper and lower substructures, respectively. $x_{I}$ represents the displacement of the floor immediately above the isolation inter-story.

Equations (1) to (3) are rewritten to focus on the inter-story seismic isolation problem: Equation (4) is obtained by dividing Equation (1) by $m_{U}$, Equation (6) is obtained by dividing Equation (3) by $m_{L}$, and Equation (5) is obtained by adding Equations (2) and (3) and dividing the resulting equation by $m_{U}$ :

$$
\begin{gathered}
\ddot{x}_{U}+\omega_{U}^{2}\left(x_{U}-x_{I}\right)=-\ddot{y}_{0} \\
\ddot{x}_{U}+\frac{1}{\mu_{U}} \ddot{x}_{I}+2\left(1+\frac{1}{\mu_{U}}\right) h_{I} \omega_{I}\left(\dot{x}_{I}-\dot{x}_{L}\right)+\left(1+\frac{1}{\mu_{U}}\right) \omega_{I}^{2}\left(x_{I}-x_{L}\right)=-\left(1+\frac{1}{\mu_{U}}\right) \ddot{y}_{0} \\
\ddot{x}_{L}-2 \mu_{L} h_{I} \omega_{I}\left(\dot{x}_{I}-\dot{x}_{L}\right)-\mu_{L} \omega_{I}^{2}\left(x_{I}-x_{L}\right)+\omega_{L}^{2} x_{L}=-\ddot{y}_{0}
\end{gathered}
$$

Here,

$$
\begin{gathered}
\omega_{U}^{2}=\frac{k_{U}}{m_{U}} \\
\omega_{I}^{2}=\frac{k_{I}}{m_{U}+m_{I}} \\
\omega_{L}^{2}=\frac{k_{L}}{m_{L}}
\end{gathered}
$$




$$
\begin{gathered}
2 h_{I} \omega_{I}=\frac{c_{I}}{m_{U}+m_{I}} \\
\mu_{U}=\frac{m_{U}}{m_{I}} \\
\mu_{L}=\frac{m_{U}+m_{I}}{m_{L}}
\end{gathered}
$$

$\omega_{U}$ is the natural circular frequency of the upper substructure (independent of the other structural parts). Similarly, $\omega_{L}$ is the natural circular frequency of the lower substructure. $\omega_{I}$ and $h_{I}$ are the natural circular frequency of isolation and the damping ratio of the damper, respectively, when the upper substructure is assumed to be rigid. $\mu_{U}$ is the mass ratio $m_{U} /$ $m_{I}$, and $\mu_{L}$ is the ratio of the total mass above the inter-story to mass of the lower substructure. Equations (11) and (12) can be combined to obtain the following mass ratio equation:

$$
m_{U}: m_{I}: m_{L}=\frac{\mu_{U} \mu_{L}}{1+\mu_{U}}: \frac{\mu_{L}}{1+\mu_{U}}: 1
$$

For analytical convenience, the motion of Equations (4) to (6) is expressed in the matrix and vector form as follows:

$$
\begin{aligned}
\left\{\begin{array}{l}
\ddot{x}_{U} \\
\ddot{x}_{I} \\
\ddot{x}_{L}
\end{array}\right\}+\left[\begin{array}{ccc}
0 & 0 & 0 \\
0 & 2\left(1+\mu_{U}\right) h_{I} \omega_{I} & -2\left(1+\mu_{U}\right) h_{I} \omega_{I} \\
0 & -2 \mu_{L} h_{I} \omega_{I} & 2 \mu_{L} h_{I} \omega_{I}
\end{array}\right]\left\{\begin{array}{l}
\dot{x}_{U} \\
\dot{x}_{I} \\
\dot{x}_{L}
\end{array}\right\} \\
+\left[\begin{array}{ccc}
\omega_{U}^{2} & -\omega_{U}^{2} & 0 \\
-\mu_{U} \omega_{U}^{2} & \mu_{U} \omega_{U}^{2}+\left(1+\mu_{U}\right) \omega_{I}^{2} & -\left(1+\mu_{U}\right) \omega_{I}^{2} \\
0 & -\mu_{L} \omega_{I}^{2} & \omega_{L}^{2}+\mu_{L} \omega_{I}^{2}
\end{array}\right]\left\{\begin{array}{l}
x_{U} \\
x_{I} \\
x_{L}
\end{array}\right\}
\end{aligned}
$$

$-\left\{\begin{array}{l}1 \\ 1 \\ 1\end{array}\right\} \ddot{y}_{0}$

When the state vector is composed of the relative velocities and displacements, the corresponding state equation is

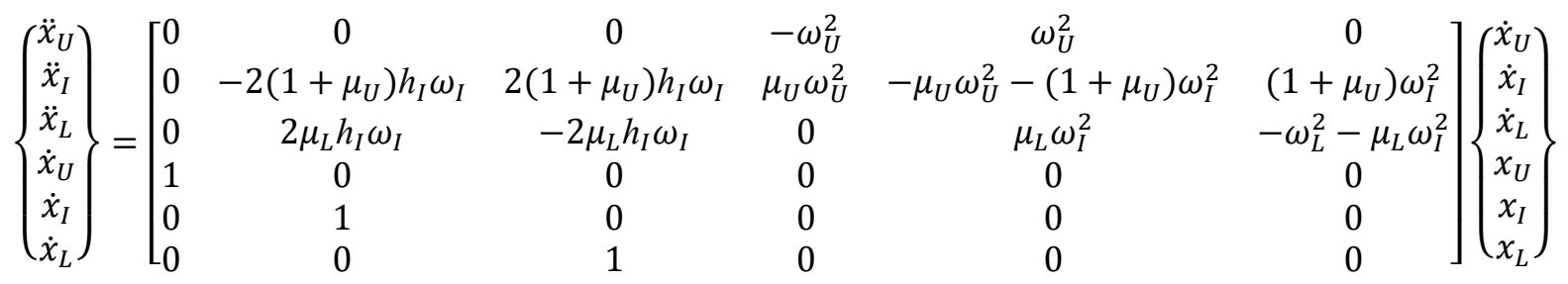




$$
-\left\{\begin{array}{l}
1 \\
1 \\
1 \\
0 \\
0 \\
0
\end{array}\right\} \ddot{y}_{0}
$$

\subsection{Characteristic equation for pole allocation}

The analytical model has three sets of conjugate poles under practical circumstances. For the isolation control target, $\omega_{i}$ and $h_{i}$ are defined as the natural circular frequency and the corresponding damping ratio, respectively, in the $i$-th mode. With the Laplace operation $s(=$ $i \omega ; \omega$ is the circular frequency), the target characteristic equation is

$$
\left(s^{2}+2 h_{1} \omega_{1} s+\omega_{1}^{2}\right)\left(s^{2}+2 h_{2} \omega_{2} s+\omega_{2}^{2}\right)\left(s^{2}+2 h_{3} \omega_{3} s+\omega_{3}^{2}\right)=0
$$

This equation can be rewritten in the following polynomial form:

$$
\begin{gathered}
s^{6}+2\left(h_{1} \omega_{1}+h_{2} \omega_{2}+h_{3} \omega_{3}\right) s^{5} \\
+\left[4\left(h_{1} h_{2} \omega_{1} \omega_{2}+h_{2} h_{3} \omega_{2} \omega_{3}+h_{3} h_{1} \omega_{3} \omega_{1}\right)+\omega_{1}^{2}+\omega_{2}^{2}+\omega_{3}^{2}\right] s^{4} \\
+2\left[h_{1} \omega_{1}\left(\omega_{2}^{2}+\omega_{3}^{2}\right)+h_{2} \omega_{2}\left(\omega_{3}^{2}+\omega_{1}^{2}\right)+h_{3} \omega_{3}\left(\omega_{1}^{2}+\omega_{2}^{2}\right)+4 h_{1} h_{2} h_{3} \omega_{1} \omega_{2} \omega_{3}\right] s^{3} \\
+\left[4 \omega_{1} \omega_{2} \omega_{3}\left(h_{1} h_{2} \omega_{3}+h_{2} h_{3} \omega_{1}+h_{3} h_{1} \omega_{2}\right)+\omega_{1}^{2} \omega_{2}^{2}+\omega_{2}^{2} \omega_{3}^{2}+\omega_{3}^{2} \omega_{1}^{2}\right] s^{2} \\
+2 \omega_{1} \omega_{2} \omega_{3}\left(h_{1} \omega_{2} \omega_{3}+h_{2} \omega_{3} \omega_{1}+h_{3} \omega_{1} \omega_{2}\right) s+
\end{gathered}
$$

$\omega_{1}^{2} \omega_{2}^{2} \omega_{3}^{2}=0$

Meanwhile, the characteristic equation for Equation (15) is

$$
\left|\begin{array}{cccccc}
-s & 0 & 0 & -\omega_{U}^{2} & \omega_{U}^{2} & 0 \\
0 & -2\left(1+\mu_{U}\right) h_{I} \omega_{I}-s & 2\left(1+\mu_{U}\right) h_{I} \omega_{I} & \mu_{U} \omega_{U}^{2} & -\mu_{U} \omega_{U}^{2}-\left(1+\mu_{U}\right) \omega_{I}^{2} & \left(1+\mu_{U}\right) \omega_{I}^{2} \\
0 & 2 \mu_{L} h_{I} \omega_{I} & -2 \mu_{L} h_{I} \omega_{I}-s & 0 & \mu_{L} \omega_{I}^{2} & -\omega_{L}^{2}-\mu_{L} \omega_{I}^{2} \\
1 & 0 & 0 & -s & 0 & 0 \\
0 & 1 & 0 & 0 & -s & 0 \\
0 & 0 & 1 & 0 & 0 & -s
\end{array}\right|=0
$$

Then, the six-dimensional matrix in Equation (18) is defined as matrix $A$, and the matrix is divided into four three-dimensional sub-matrices such as $A_{11}, A_{12}, A_{21}$, and $A_{22}$ :

$$
\begin{gathered}
A=\left[\begin{array}{ll}
A_{11} & A_{12} \\
A_{21} & A_{22}
\end{array}\right] \\
A_{11}=\left[\begin{array}{ccc}
-s & 0 & 0 \\
0 & -2\left(1+\mu_{U}\right) h_{I} \omega_{I}-s & 2\left(1+\mu_{U}\right) h_{I} \omega_{I} \\
0 & 2 \mu_{L} h_{I} \omega_{I} & -2 \mu_{L} h_{I} \omega_{I}-s
\end{array}\right]
\end{gathered}
$$




$$
\begin{gathered}
A_{12}=\left[\begin{array}{ccc}
-\omega_{U}^{2} & \omega_{U}^{2} & 0 \\
\mu_{U} \omega_{U}^{2} & -\mu_{U} \omega_{U}^{2}-\left(1+\mu_{U}\right) \omega_{I}^{2} & \left(1+\mu_{U}\right) \omega_{I}^{2} \\
0 & \mu_{L} \omega_{I}^{2} & -\omega_{L}^{2}-\mu_{L} \omega_{I}^{2}
\end{array}\right] \\
A_{21}=\left[\begin{array}{ccc}
1 & 0 & 0 \\
0 & 1 & 0 \\
0 & 0 & 1
\end{array}\right] \\
A_{22}=\left[\begin{array}{ccc}
-S & 0 & 0 \\
0 & -S & 0 \\
0 & 0 & -S
\end{array}\right]
\end{gathered}
$$

The determinant of matrix $A$ can be calculated using the following sub-matrices:

$$
|A|=\left|A_{22}\right|\left|A_{11}-A_{12} A_{22}^{-1} A_{21}\right|
$$

As a result, the determinant is expressed in the polynomial form:

$$
\begin{aligned}
s^{6}+2(1+ & \left.\mu_{U}+\mu_{L}\right) h_{I} \omega_{I} s^{5}+\left[\left(1+\mu_{U}\right) \omega_{U}^{2}+\left(1+\mu_{U}+\mu_{L}\right) \omega_{I}^{2}+\omega_{L}^{2}\right] s^{4} \\
& +2 h_{I} \omega_{I}\left[\left(1+\mu_{U}\right)\left(1+\mu_{L}\right) \omega_{U}^{2}+\left(1+\mu_{U}\right) \omega_{L}^{2}\right] s^{3} \\
+ & {\left[\left(1+\mu_{U}\right)\left(1+\mu_{L}\right) \omega_{U}^{2} \omega_{I}^{2}+\left(1+\mu_{U}\right)\left(\omega_{U}^{2}+\omega_{I}^{2}\right) \omega_{L}^{2}\right] s^{2} } \\
+ & 2\left(1+\mu_{U}\right) h_{I} \omega_{I} \omega_{U}^{2} \omega_{L}^{2} s+\left(1+\mu_{U}\right) \omega_{U}^{2} \omega_{I}^{2} \omega_{L}^{2}=0
\end{aligned}
$$

In Equation (25), $\omega_{L}^{2}$ and $\left(1+\mu_{U}\right) \omega_{U}^{2}$ are exchangeable, and $\mu_{U}$ and $\mu_{L}$ are exchangeable. These properties result in two candidate solutions, which are expressed as Equations (50) and (51).

\subsection{Pole allocation}

The characteristic equation (25) must be designed to be equal to the target characteristic equation (17), which requires the following parameter relationships:

$$
\begin{gathered}
h_{1} \omega_{1}+h_{2} \omega_{2}+h_{3} \omega_{3}=\left(1+\mu_{U}+\mu_{L}\right) h_{I} \omega_{I} \\
4\left(h_{1} h_{2} \omega_{1} \omega_{2}+h_{2} h_{3} \omega_{2} \omega_{3}+h_{3} h_{1} \omega_{3} \omega_{1}\right)+\omega_{1}^{2}+\omega_{2}^{2}+\omega_{3}^{2} \\
=\left(1+\mu_{U}\right) \omega_{U}^{2}+\left(1+\mu_{U}+\mu_{L}\right) \omega_{I}^{2}+\omega_{L}^{2} \\
h_{1} \omega_{1}\left(\omega_{2}^{2}+\omega_{3}^{2}\right)+h_{2} \omega_{2}\left(\omega_{3}^{2}+\omega_{1}^{2}\right)+h_{3} \omega_{3}\left(\omega_{1}^{2}+\omega_{2}^{2}\right)+4 h_{1} h_{2} h_{3} \omega_{1} \omega_{2} \omega_{3} \\
=h_{I} \omega_{I}\left[\left(1+\mu_{U}\right)\left(1+\mu_{L}\right) \omega_{U}^{2}+\left(1+\mu_{U}\right) \omega_{L}^{2}\right] \\
4 \omega_{1} \omega_{2} \omega_{3}\left(h_{1} h_{2} \omega_{3}+h_{2} h_{3} \omega_{1}+h_{3} h_{1} \omega_{2}\right)+\omega_{1}^{2} \omega_{2}^{2}+\omega_{2}^{2} \omega_{3}^{2}+\omega_{3}^{2} \omega_{1}^{2} \\
=\left(1+\mu_{U}\right)\left(1+\mu_{L}\right) \omega_{U}^{2} \omega_{I}^{2}+\left(1+\mu_{U}\right)\left(\omega_{U}^{2}+\omega_{I}^{2}\right) \omega_{L}^{2} \\
\omega_{1} \omega_{2} \omega_{3}\left(h_{1} \omega_{2} \omega_{3}+h_{2} \omega_{3} \omega_{1}+h_{3} \omega_{1} \omega_{2}\right)=\left(1+\mu_{U}\right) h_{I} \omega_{I} \omega_{U}^{2} \omega_{L}^{2} \\
\omega_{1}^{2} \omega_{2}^{2} \omega_{3}^{2}=\left(1+\mu_{U}\right) \omega_{U}^{2} \omega_{I}^{2} \omega_{L}^{2}
\end{gathered}
$$

These equations have six designed unknown parameters to be solved: $\omega_{U}, \omega_{I}, \omega_{L}, h_{I}, \mu_{U}$, 
and $\mu_{L}$. A significant relationship can be obtained by multiplying Equation (30) with $\omega_{I}$ and substituting Equation (31) into the multiplied equation:

$$
\begin{aligned}
& \frac{h_{I}}{\omega_{I}}=\frac{h_{1}}{\omega_{1}}+\frac{h_{2}}{\omega_{2}}+\frac{h_{3}}{\omega_{3}} \\
& h_{I}=\omega_{I}\left(\frac{h_{1}}{\omega_{1}}+\frac{h_{2}}{\omega_{2}}+\frac{h_{3}}{\omega_{3}}\right)
\end{aligned}
$$

Either Equation (32) or Equation (33) constrains the two parameters $\omega_{I}$ and $h_{I}$ for inter-story seismic isolation. $h_{I}$ can be removed by substituting Equation (33) into Equations (26), (28), and (30). Equations (26) to (30) can be condensed to the following equations with the five unknown parameters $\omega_{U}, \omega_{I}, \omega_{L}, \mu_{U}$, and $\mu_{L}$ :

$$
\begin{gathered}
\left(1+\mu_{U}+\mu_{L}\right) \omega_{I}^{2}=b_{1} \\
\left(1+\mu_{U}\right) \omega_{U}^{2}+\left(1+\mu_{U}+\mu_{L}\right) \omega_{I}^{2}+\omega_{L}^{2}=b_{2} \\
\left(1+\mu_{U}\right)\left(1+\mu_{L}\right) \omega_{U}^{2} \omega_{I}^{2}+\left(1+\mu_{U}\right) \omega_{L}^{2} \omega_{I}^{2}=b_{3} \\
\left(1+\mu_{U}\right)\left(1+\mu_{L}\right) \omega_{U}^{2} \omega_{I}^{2}+\left(1+\mu_{U}\right)\left(\omega_{U}^{2}+\omega_{I}^{2}\right) \omega_{L}^{2}=b_{4} \\
\left(1+\mu_{U}\right) \omega_{U}^{2} \omega_{I}^{2} \omega_{L}^{2}=b_{5}
\end{gathered}
$$

in which

$$
\begin{gathered}
b_{1}=\frac{h_{1} \omega_{1}+h_{2} \omega_{2}+h_{3} \omega_{3}}{\frac{h_{1}}{\omega_{1}}+\frac{h_{2}}{\omega_{2}}+\frac{h_{3}}{\omega_{3}}} \\
b_{2}=4\left(h_{1} h_{2} \omega_{1} \omega_{2}+h_{2} h_{3} \omega_{2} \omega_{3}+h_{3} h_{1} \omega_{3} \omega_{1}\right)+\omega_{1}^{2}+\omega_{2}^{2}+\omega_{3}^{2} \\
b_{3}=\frac{h_{1} \omega_{1}\left(\omega_{2}^{2}+\omega_{3}^{2}\right)+h_{2} \omega_{2}\left(\omega_{3}^{2}+\omega_{1}^{2}\right)+h_{3} \omega_{3}\left(\omega_{1}^{2}+\omega_{2}^{2}\right)+4 h_{1} h_{2} h_{3} \omega_{1} \omega_{2} \omega_{3}}{\frac{h_{1}}{\omega_{1}}+\frac{h_{2}}{\omega_{2}}+\frac{h_{3}}{\omega_{3}}} \\
b_{4}=4 \omega_{1} \omega_{2} \omega_{3}\left(h_{1} h_{2} \omega_{3}+h_{2} h_{3} \omega_{1}+h_{3} h_{1} \omega_{2}\right)+\omega_{1}^{2} \omega_{2}^{2}+\omega_{2}^{2} \omega_{3}^{2}+\omega_{3}^{2} \omega_{1}^{2}=b_{4} \\
b_{5}=\frac{\omega_{1} \omega_{2} \omega_{3}\left(h_{1} \omega_{2} \omega_{3}+h_{2} \omega_{3} \omega_{1}+h_{3} \omega_{1} \omega_{2}\right)}{\frac{h_{1}}{\omega_{1}}+\frac{h_{2}}{\omega_{2}}+\frac{h_{3}}{\omega_{3}}}
\end{gathered}
$$

The difference between Equations (36) and (37) is

$$
\left(1+\mu_{U}\right) \omega_{U}^{2} \omega_{L}^{2}=b_{4}-b_{3}
$$

Substituting Equation (44) into Equation (38) yields $\omega_{I}$ :

$$
\begin{gathered}
\left(b_{4}-b_{3}\right) \omega_{I}^{2}=b_{5} \\
\omega_{I}=\sqrt{\frac{b_{5}}{b_{4}-b_{3}}}
\end{gathered}
$$


Similarly, substituting Equation (46) into Equation (33) yields $h_{I}$ :

$$
h_{I}=\sqrt{\frac{b_{5}}{b_{4}-b_{3}}}\left(\frac{h_{1}}{\omega_{1}}+\frac{h_{2}}{\omega_{2}}+\frac{h_{3}}{\omega_{3}}\right)
$$

The next step is to obtain both $\omega_{L}^{2}$ and $\left(1+\mu_{U}\right) \omega_{U}^{2}$. Equations (34) and (35) yield the following:

$$
\left(1+\mu_{U}\right) \omega_{U}^{2}+\omega_{L}^{2}=b_{2}-b_{1}
$$

Equations (44) and (48) imply that both $\left(1+\mu_{U}\right) \omega_{U}^{2}$ and $\omega_{L}^{2}$ are solutions for the following quadratic equation with respect to $z$ :

$$
z^{2}+\left(b_{1}-b_{2}\right) z+\left(b_{4}-b_{3}\right)=0
$$

There are two possible solutions: Solution (50) or (51). This characteristic originates from the symmetry of the characteristic equation (25): $\omega_{L}^{2}$ and $\left(1+\mu_{U}\right) \omega_{U}^{2}$ are commutative, and $\mu_{L}$ and $\mu_{U}$ are commutative. Reference 26 presents a similar exchangeability characteristic between the second and third modes.

$$
\begin{aligned}
& \left(1+\mu_{U}\right) \omega_{U}^{2}=\frac{b_{2}-b_{1}+\sqrt{\left(b_{2}-b_{1}\right)^{2}-4\left(b_{4}-b_{3}\right)}}{2} \text { and } \omega_{D}^{2}=\frac{b_{2}-b_{1}-\sqrt{\left(b_{2}-b_{1}\right)^{2}-4\left(b_{4}-b_{3}\right)}}{2} \\
& \omega_{D}^{2}=\frac{b_{2}-b_{1}+\sqrt{\left(b_{2}-b_{1}\right)^{2}-4\left(b_{4}-b_{3}\right)}}{2} \text { and }\left(1+\mu_{U}\right) \omega_{U}^{2}=\frac{b_{2}-b_{1}-\sqrt{\left(b_{2}-b_{1}\right)^{2}-4\left(b_{4}-b_{3}\right)}}{2}
\end{aligned}
$$

This exchangeability characteristic implies that theoretically, the two target vibration modes control the upper and lower substructures in two ways. Equation (34) can be transformed into Equation (52):

$$
1+\mu_{L}=\frac{b_{1}}{\omega_{I}^{2}}-\mu_{U}
$$

Substituting Equation (52) into Equation (36),

$$
\begin{gathered}
\left(1+\mu_{U}\right)\left(\frac{b_{1}}{\omega_{I}^{2}}-\mu_{U}\right) \omega_{U}^{2}+\left(1+\mu_{U}\right) \omega_{D}^{2}=\frac{b_{3}}{\omega_{I}^{2}} \\
\mu_{U}=\frac{\frac{b_{3}-b_{1}\left(1+\mu_{U}\right) \omega_{U}^{2}}{\omega_{I}^{2}}-\omega_{D}^{2}}{\omega_{D}^{2}-\left(1+\mu_{U}\right) \omega_{U}^{2}}
\end{gathered}
$$

It is observed that $\mu_{U}$ has two possible values owing to the exchangeable characteristic of 
$\left(1+\mu_{U}\right) \omega_{U}^{2}$ and $\omega_{L}^{2}$. Equations (52) and (54) obtain the mass ratio of $\mu_{L}$.

$$
\mu_{D}=\frac{b_{1}}{\omega_{I}^{2}}-\mu_{U}-1
$$

The newly introduced process describes six designed parameters: $\omega_{U}, \omega_{I}, \omega_{L}, h_{I}, \mu_{U}$ and $\mu_{L}$ can be obtained in the closed form from three target pairs of $\omega_{i}$ and $h_{i}$.

The solution is the ideal structural system for determining the control target. The essential concern is whether inter-story seismic isolation is applicable under the expected modal target. That is, how is the inter-story seismic isolation constrained by the expected target?

\subsection{Simplification for TMD}

When a TMD passively controls an S-DOF undamped building model, the upper substructure can be assumed to be rigid. Then, one mode can be removed from Equation (32) as

$$
\frac{h_{I}}{\omega_{I}}=\frac{h_{1}}{\omega_{1}}+\frac{h_{2}}{\omega_{2}}
$$

In this case, $\omega_{I}$ and $h_{I}$ are re-defined as the natural circular frequency and damping ratio of the TMD, respectively. The optimal tuning frequency and damping ratio are introduced as follows based on the fixed-point theory by Den Hartog ${ }^{27}$ :

Optimal tuning frequency

$$
\frac{\omega_{I}}{\omega_{L}}=\frac{1}{1+\mu_{L}}
$$

Optimal damping ratio

$$
h_{I}=\sqrt{\frac{3 \mu_{L}}{8\left(1+\mu_{L}\right)}}
$$

The two natural circular frequencies at the fixed points are

$$
\omega_{1}=\omega_{L} \sqrt{\frac{1-\sqrt{\frac{\mu_{L}}{2+\mu_{L}}}}{1+\mu_{L}}} \text { and } \omega_{2}=\omega_{L} \sqrt{\frac{1+\sqrt{\frac{\mu_{L}}{2+\mu_{L}}}}{1+\mu_{L}}}
$$

By assuming that the target damping ratios in both the modes are equal to $h$ and substituting Equations (57), (58), and (59) into Equation (56), the target damping ratio is

$$
h=\frac{\sqrt{\frac{3 \mu_{L}}{4\left(2+\mu_{L}\right)}}}{\sqrt{1-\sqrt{\frac{\mu_{L}}{2+\mu_{L}}}}+\sqrt{1+\sqrt{\frac{\mu_{L}}{2+\mu_{L}}}}}
$$


Now, applying the Taylor series approximation $\sqrt{1 \pm x}=1 \pm x / 2$ to Equation (60), it is rewritten as

$$
h=\frac{1}{4} \sqrt{\frac{3 \mu_{L}}{2+\mu_{L}}}
$$

Under optimal tuning by Den Hartog, Equation (61) approximates the additional damping through the ratio of the mass of the TMD to that of the installed S-DOF structure. Figure 2 shows the dependency of the control effectiveness on the mass ratio. Equation (61) can approximate Equation (60) very well. The inverse approach can conveniently obtain the supplemental damping. Similar damping effect equations may be obtained using other optimizations ${ }^{28,29}$.

As Equations (57) and (58) indicate one example, the traditional TMD optimization methods ${ }^{27-29}$ propose $\omega_{I}$ for the auxiliary mass and $h_{I}$ for the damper from the mass ratio $\mu_{L}$, while they do not predict the additional damping ratio $h$ for the structure directly. The optimization flow does not respond well to the fact that it is the additional damping effect which finally controls the TMD. The traditional methods might design the TMD through trial and error. However, based on Equation (61), $\mu_{L}$ is obtained after the target additional damping ratio $h$ is determined, and the introduced $\mu_{L}$ proposes $\omega_{I}$ and $h_{I}$. The pole allocation for TMD indicates an inverse design flow for the TMD optimization, which matches the performance-based design.

\section{VERIFICATION USING NUMERICAL EXAMPLES}

\subsection{0-DOF models}

Figure 3 shows a 10-DOF lumped-mass shear model that is used to explain the mathematical equations introduced in Section 2. The model has a five-degree-of-freedom (5-DOF) lower substructure, a 5-DOF upper substructure, and an inter-story where the isolator and the corresponding damper are installed. The upper substructure includes the isolation story. This model resembles 10-DOF models applied in past research to investigate the modal coupling between upper and lower substructures ${ }^{2,3}$.

The weight of each lumped mass is $1.0 \times 10^{6} \mathrm{~kg}$. The parameters $k_{6}$ and $c_{6}$ represent the isolator's spring and damper damping coefficient, respectively. The other parameters represent the shear stiffness values and damping coefficients of individual stories in the substructures. The stiffness values from $k_{1}$ to $k_{5}$ are fixed such that the first natural frequency of the lower substructure is $2.0 \mathrm{~Hz}$. $k_{6}$ is fixed as $12,337 \mathrm{kN} / \mathrm{m}$, so that the natural frequency of the isolator is $0.25 \mathrm{~Hz}$ when the upper substructure is assumed to be rigid. $c_{6}$ is fixed as $3,142 \mathrm{kNs} / \mathrm{m}$, so that the damping ratio of the damper is $20 \%$ under the above rigidity assumption. The damping sub-matrix with $c_{1}$ to $c_{5}$ for the lower substructure is proportional to the corresponding stiffness matrix, which implies internal viscous damping. The damping ratio 
for the lower substructure is $2 \%$ at $2.0 \mathrm{~Hz}$. Similar to References 2 and 3, three models are prepared for the upper substructure so that the second natural frequencies are $1.8 \mathrm{~Hz}$ for Model A, 2.0 Hz for Model B, and 3.0 Hz for Model C. Both references are useful in confirming the closed-form mathematical equations introduced in Section 2. A comparison of the three models reveals that the only changeable dynamic property is the ratio of the second natural frequency of the upper substructure to the first natural frequency of the lower substructure. These ratios are $0.9(=1.8 \mathrm{~Hz} / 2.0 \mathrm{~Hz})$ for Model A, $1.0(=2.0 \mathrm{~Hz} / 2.0 \mathrm{~Hz})$ for Model B, and $1.5(3.0 \mathrm{~Hz} / 2.0 \mathrm{~Hz})$ for Model C. In the upper substructure, the first natural frequency forms the dominant mode in the inter-story. The damping ratio for the upper substructure is $2 \%$ at its second natural frequency. Table 1 lists the stiffness values and damping ratios for the three 10 -DOF models.

Figure 4 illustrates the lowest three modal shapes with excitations' participation factors of the 10-DOF models, and Table 2 indicates the corresponding natural frequencies and damping ratios. Similar to References 3, 6, and 22, the modal shapes are obtained by the classical eigenvalue problem because the participation factors for input excitation are considered to be real numbers. Larger inter-story drifts are observed in the first modes of all the models. In Model A, the third overall mode is the predominant mode of the lower substructure, and the second and third modes have similar modal shapes with different signs in the upper substructure. The third mode has a significantly larger amplitude than the second mode, in the inter-story mode. Although Model B has a tendency similar to that of Model A, the modal amplitudes in the second and third modes are larger than those in Model A in the upper substructure, and the second mode stimulates the lower substructure. Model $\mathrm{C}$ has the simplest modal shape among the three. The upper substructure is not stimulated in the second and third modes. These phenomena have already been found by References 2 and 3 .

It has been indicated that the mode with a small inter-story drift cannot accept a high damper capacity in the inter-story. Table 2 clearly shows the low damping ratio in the second mode of Model B. This is the so-called modal coupling/interaction problem to be considered in inter-story seismic isolation.

\subsection{Verification of Equation (32)}

Now, Equation (32) is transformed into the following equation, and its applicability is assessed by using the lowest three vibration models shown in Table 2.

$$
\frac{h_{I}}{f_{I}}=\frac{h_{1}}{f_{1}}+\frac{h_{2}}{f_{2}}+\frac{h_{3}}{f_{3}}
$$

where $f_{I}$ is the natural frequency of the isolator and $f_{i}$ is the $i$-th natural frequency in each target mode. $f_{I}$ and $f_{i}$ respond to the circular natural frequencies $\omega_{I}$ and $\omega_{i}$, respectively.

When the upper substructure is rigid, the natural frequency of the isolator is $0.25 \mathrm{~Hz}$ and the corresponding damping ratio is $20 \%$. These values provide $80.00(=20 / 0.25$, unit: $\% / \mathrm{Hz})$ 
to the left side of Equation (62). When the lowest three vibration modes in Table 2 are considered, the right side is 80.99 for Model A, 81.04 for Model B, and 81.07 for Model C. This good agreement verifies Equation (62) as the modal property relationship.

In general, the natural frequency and damping ratio in the first mode are very close to the natural frequency and damping ratio of the inter-story ${ }^{25}$. $f_{I}$ is nearly equal to $f_{1}$, and the difference between $h_{I}$ and $h_{1}$ is marginal. This tendency results in the following approximation:

$$
\frac{h_{I}-h_{1}}{f_{I}} \cong \frac{h_{2}}{f_{2}}+\frac{h_{3}}{f_{3}}
$$

This implies a tradeoff relationship between the damping of the second mode and that of the third mode.

For an inter-story seismically isolated building, the preliminary structural design determines the equivalent stiffness and damping ratio for its inter-story. In other words, it is necessary to determine parameters $\omega_{I}$ and $h_{I}$ in this study. Equation (62) clearly describes two design approaches: (1) When structural designers first assume the control target as three dominant vibration modes on the right side, it automatically leads the isolator's parameters on the left side; and (2) When they first assume the isolator's parameters, the assumption limits the control target. The first approach means the design flow from the right side to the left side, and the second one vice versa. Particularly at the initial design stage, Equation (62) is linked directly to the design of inter-story isolation. In actual design, an interaction between the first and second approaches seems to become the important and practical work. In practical applications, the structural design of the upper and lower substructures cannot be flexibly adjusted. This means that the approximate values $\omega_{2}$ and $\omega_{3}$ have already been determined in Equation (62). However, Reference 10 introduces the tuning of stiffness for the lower substrucure.

\subsection{Simplified 3-DOF model}

Substituting the lowest three modal properties in Table 2 into Equation (16) yields the modal shapes of the simplified 3-DOF shown in Figure 5 and the mass distribution indicated in Table 3. In the figure, the numbers on the vertical axes indicate three lumped masses: No.1 for $m_{L}$, No.2 for $m_{I}$, and No.3 for $m_{U}$.

Each model has two sub-models responding to the alternative Equations (50) and (51). The characteristics equation (16) has two possibilities to represent the second and third modes. For Model A, Figure 5(1) shows the second overall mode for the upper substructure and the third overall mode for the lower substructure, and Figure 5(4) shows the second overall mode for the lower substructure and the third overall mode for the upper structure. Both the sub-models can express the same control target. Similar inversions can be observed in Models B and C. However, Figures (1), (2), and (6) agree more with the 10-DOF modal shapes than with 
Figures (4), (5), and (3), respectively.

Table 3 similarly shows two possibilities of mass distribution in response to the modal amplitudes in Figure 5. The mass ratio is obtained using Equation (13). Although Section 2 defines $m_{I}$ as the mass of the floor immediately above the isolation inter-story, $m_{I}$ appears to be larger than the value according to this definition. It is observed that $m_{I}$ is the equivalent mass above the inter-story and below the upper substructure. That is, the mass distribution cannot be used directly for the initial structural design.

\subsection{Improvement of low damping in Model $B$}

The second mode in Model B has a low damping ratio of $2 \%$. This is a significant issue in the inter-story seismic isolation of buildings. When an earthquake has a large frequency component in the second mode, the upper substructure is excited owing to this low damping. This sub-section attempts to improve this low value by increasing the target damping ratio only in the second mode. That is, the three natural frequencies are fixed as $0.243,1.985$, and $2.043 \mathrm{~Hz}$, and the two damping ratios in the first and third modes are fixed as $18.2 \%$ and $10.7 \%$, respectively. Figure 6 shows the variations in the natural frequencies and mass ratios as the damping ratio in the second mode of Model B increases.

In Model B-1, as this damping ratio increases, the natural frequency of the upper substructure matching with $\omega_{U}$ decreases, and the natural frequency of the lower substructure matching with $\omega_{L}$ increases. In Model B-2, the natural frequencies of the upper and lower substructures decrease. The natural frequency of the isolator matching with $\omega_{I}$ is almost similar. In both the sub-models, the mass ratios of the upper substructures increase as shown in Figure 6(2). Figure 7 selects three modal shapes with damping ratios of $5 \%, 10 \%$, and $15 \%$ in the second mode, from Figure 6 . The mass of the upper substructure mainly increases with additional damping. In three cases of the sub-model, variations in the modal shapes can be omitted when Figure 7 is compared with Figure 5. The upper substructure lowers the dominant natural frequency with an increase in its mass. This indicates that the flexibility of the upper substructure provides the additional damping ratio to the second mode.

The right side of Equation (63) implies this damping strategy. The smaller the natural frequency in the denominator, the larger is the damping ratio. The equation indicates the tradeoff relationship between the second and third modes under the condition that the left side is constant. Furthermore, it demonstrates that the relationship between the amplification and reduction of seismic response creates a pair of physical phenomena.

\subsection{Interpretation of earthquake responses of 10-DOF models}

In general, structural seismic responses depend on the dynamic properties of input excitations, which sometimes makes it difficult to extract essential characteristics from earthquake-resistant structures. One of the advantages of this study is that it considers inter-story isolation independently of earthquake excitations. This advantage has already been indicated in References 2, 3, 25 and 26 that handle the inter-story isolation as eigenvalue problems. However, the simplified 3-DOF model cannot consider higher vibration modes. 
This subsection investigates the applicability of the simplified model with an interpretation of earthquake response simulation of the 10-DOF models under the equivalent linearization assumption.

In the seismic response analyses, the 10-DOF models are excited by four recorded earthquake accelerations: 1940 El Centro wave (NS component), 1952 Taft wave (EW component), 1968 Hachinohe wave (NS component) and 1995 JMA Kobe (NS component). For the analyses, their amplitudes were normalized so that their peak velocities became 50 $\mathrm{cm} / \mathrm{s}$. The corresponding peak accelerations obtained were $510 \mathrm{~cm} / \mathrm{s}^{2}$ for El Centro, $497 \mathrm{~cm} / \mathrm{s}^{2}$ for Taft, $334 \mathrm{~m} / \mathrm{s}^{2}$ for Hachinohe and $425 \mathrm{~cm} / \mathrm{s}^{2}$ for JMA Kobe.

Figure 8 shows acceleration and displacement response spectra of the input earthquakes. Figure 9 shows the peak structural responses of Models A, B and C. The peak displacements of the isolators in Table 4 match with Figure 9. The comparison shown in Figure 9 clearly indicates that Model $\mathrm{C}$ is the best of three candidate models, because the responses of both the substructures are suppressed well, and their response distributions are relatively simple in the upper substructure. Additionally, the flexibility of the upper part seems to be a blocker for suppression of vibration of the lower part. In Models A and B, the peak accelerations at the 8th lumped-mass are the smallest in the upper substructure. This tendency is predicted to some extent by the second and third vibration modes of Models A-1 and B-1 in Figure 5. In Model C, the isolator's displacements cannot be seen apparently under El Centro and Hachinohe excitations, which has already appeared in the second mode of Model C-1 and the third mode of Model C-2 in Figure 5. The earthquake simulation results are followed qualitatively by the 3 -DOF models simplified from the 10-DOF models. On the other hand, Table 4 indicates that the isolator's displacements in Model $\mathrm{C}$ have almost the same amplitudes under four excitations. This apparent mismatch occurs due to the negligence of time and phase in Figure 9 that indicate only the absolute values. In fact, the upper substructure sometimes vibrates in the opposite direction of the lower substructure. With $4.0 \mathrm{~s}$ for the natural period ( $f_{I}$ is $0.25 \mathrm{~Hz}$ ) and damping ratio $\left(h_{I}\right) 20 \%$, the isolator's peak displacements in models A and B match the displacement spectra. However, those of model C do not match them. This limitation in understanding evidently requires earthquake response simulation. Although the simplified models based on the pole allocation are limited to predicting the seismic responses in each story, nevertheless they are useful in understanding the dynamic properties in the initial structural design.

\section{CONCLUSIONS}

The inverse problem is formulated based on the pole allocation method in control theory for a building with an inter-story seismic isolation system. The structure is modeled as a 3-DOF lumped-mass shear system, and the control target is set as the natural frequencies and the corresponding damping ratios in the three vibration modes. To achieve this target, the introduced solution provides the natural frequencies of the lower substructure, upper 
substructure, and isolator with the damper capacity. It also provides the mass distribution for the three lumped masses as the ideal structural system.

The closed mathematical expression is effective for a further understanding of the general and essential dynamic characteristics of inter-story seismic isolation. The formulation is transformed to express the relationships between the supplemental damping ratio and mass ratio in the TMD system.

The newly introduced formulation clarifies how both the isolator's natural frequency and damper's capacity are related to the dominant natural frequencies of both the substructures and to the target modal damping ratios. The formulation demonstrates that the same control target has two possibilities to form the target structural system with inter-story seismic isolation, which theoretically controls the upper and lower substructures in two ways. This can explain the modal coupling and interaction effect between the upper and lower substructures as the tradeoff relationship between the second and third modes. Furthermore, the solution is applied to directly estimate the damping effect of TMD. The inverse problem approach provides a basic design method for inter-story seismic isolation of a building, particularly at the initial design stage.

\section{REREFENCES}

1. Meirovitch L. Dynamics and Control of Structures. John Wiley \& Sons; 1990. 183-185.

2. Kobayashi M, Koh T. Analytical study of modal coupling effect on mid-story isolation system by eigen value analysis and random vibration analysis. Summaries of Technical Papers of Annual Meeting, Architectural Institute of Japan 2004; B-2 (Structure II): 333-334 (in Japanese).

3. Kobayashi M, Koh T. Modal coupling effects of mid-story isolated buildings. In: Proceedings of 14th World Conference on Earthquake Engineering 2008; Beijing, China: 8 pages, Article ID 05-01-0230.

4. Ogura K, Maezawa S, Tsujita O, Kobayashi J, Nakata Y. Seismic isolation retrofit at mid-story and base -Structural design-. AIJ Journal of Technology and Design 1997;(5):37-41 (in Japanese).

5. Murakami K, Kitamura H, Ozaki H, Yamanashi T. Design of a building with seismic isolation system at the mid-story. AIJ Journal of Technology and Design 1999;(7):51-56 (in Japanese).

6. Murakami K, Kitamura H, Ozaki H, Teramoto T. Design and analysis of a building with the middle-story isolation structural system. In: Proceedings of 12th World Conference on Earthquake Engineering 2000; Aukland, New Zealand: 8 pages, Article ID 0857.

7. Sueoka T, Torii S, Tsuneki Y. The application of response control design using middle-story isolation system to high-rise building. In: Proceedings of 13th World Conference on Earthquake Engineering 2004; Vancouver, Canada: 15 pages, Article ID 3457. 
8. Tsuneki Y, Torii S, Murakami K, Sueoka T. Middle-story isolated structural system of high-rise building. In: Proceedings of 14th World Conference on Earthquake Engineering 2008; Beijing, China: 8 pages, Article ID S05-01-023.

9. Kobayashi M, Sasaki D. Making a seismic design database of mid-story isolated buildings and structural property evaluation based on response prediction method. AIJ Journal of Technology and Design 2009;15(29):65-70 (in Japanese).

10. Nakamizo D, Koitabashi Y. Structural design of mid-story isolated high-rise building -Roppongi Grand Tower-. Int J High-rise Buildings 2018;7(3):233-242.

11. Mele E, Faiella D. Inter-story isolation systems (IIS) for tall buildings: Design consideration. CTBUH Journal 2018;(2):34-41.

12. Ogura K, Takayama M, Tsujita O, Kimura Y, Wada A. Seismic response of mid-story isolated buildings. J Struct Constr Eng, AIJ 1999;(516):99-104 (in Japanese).

13. Kobayashi M, Koh T. Earthquake response prediction and aseismic performance of mid-story isolated system. J Struct Constr Eng, AIJ 2002;(558):109-116 (in Japanese).

14. Yamashita T, Mukai Y, Inoue Y. Evaluation and synthesis for aseismic responses of structural system with inter-story isolation devices. $J$ Struct Constr Eng, AIJ 2005;(591):35-42 (in Japanese).

15. Kobayashi M, Koh T. Earthquake response prediction and rationalization of dynamic design of mid-story isolated buildings. J Struct Constr Eng, AIJ 2005;(592):51-57 (in Japanese).

16. Anajafi H, Medina RA. Partial mass isolation system for seismic vibration control of buildings. Struct Control Health Monit 2018;25(2): 16 pages, Article ID e2088.

17. Loh C-H, Weng J-H, Chen C-H, Lu K-C. System identification of mid-story isolation building using both ambient and earthquake response data. Struct Control Health Monit 2013;20(2):139-155.

18. Zhang R, Phillip BM, Taniguchi S, Ikenaga M, Ikago K. Shake table real-time hybrid simulation techniques for the performance evaluation of buildings with inter-story isolation. Struct Control Health Monit 2017;24(10): 19 pages, Article ID e1971.

19. Murakami K, Kitamura H, Matsushima Y. The prediction for seismic responses of the two-mass model with the mid-story isolation system. J Struct Constr Eng, AIJ 2001;(549):51-59 (in Japanese).

20. Argenziano M, Faiella D, Fraldi M, Mele E. Optimum tuning frequency and damping ratios in inter-story isolation systems (non-conventional TMDs): a closed form solution. Atti del XVIII Convegno ANIDIS L'ingegneria Sismica in Italia 2019; Ascoli Piceno: SS01 190-197.

21. Kaneko K. Multipurpose passive control of mid-story isolation buildings designed to mitigate seismic response in substructure. $J$ Struct Constr Eng, AIJ 2015;80(718):1869-1879 (in Japanese).

22. Hirotani N, Hata I. A study on Building Mass Damper system using mid-story isolated 
system -A design method using the performance-based design diagram-. J Struct Constr Eng, AIJ 2018;83(753):1573-1582 (in Japanese).

23. Kelly JM. Earthquake-resistant Design with Rubber. 2nd Edition. Springer-Verlag London; 1997:43-58.

24. Moriizumi E, Kobayashi M. Study on earthquake response considered vibration characteristics of superstructure and substructure of seismically isolated buildings. In: Proceedings of 15th World Conference on Earthquake Engineering 2012; Lisbon, Portugal: 10 pages, Article ID 1792.

25. Wang S-J, Chang K-C, Hwang J-S, Lee B-H. Simplified analysis of mid-story seismically isolated buildings. Earthq Eng Struct Dyn 2011;40(2):119-133.

26. Wang S-J, Hwang J-S, Chang K-C, Lin M-H, Lee B-H. Analytical and experimental studies on midstory isolated buildings with modal coupling effect. Earthq Eng Struct Dyn 2013;42(2):201-219.

27. Den Hartog JP. Mechanical Vibrations. 4th Edition. McGraw-Hill; 1956. 87-106.

28. Warburton GB. Optimum absorber parameters for various combinations of response and excitation parameters. Earthq Eng Struct Dyn 1982;10(3):381-401.

29. Crandall SE, Mark WD, Random Vibration in Mechanical Systems. 2nd Edition. Academic Press; 1963. 80-101. 


\section{Captions for Tables}

TABLE 1 Stiffness and damping values for the three 10-DOF models

TABLE 2 Natural frequencies and damping ratios of 10-DOF models

TABLE 3 Mass ratios corresponding to Figure 6

TABLE 4 Peak displacements of isolators

\section{Captions for Figures}

FIGURE 13 -DOF lumped-mass model for inter-story seismic isolation

FIGURE 2 Additional damping ratio with respect to TMD mass ratio

FIGURE 3 10-DOF lumped-mass model for numerical verification

FIGURE 4 Modal shapes with excitations' participation factors of 10-DOF models

FIGURE 5 Modal shapes with excitations' participation factors of 3-DOF models simplified from 10-DOF models

FIGURE 6 Variations in natural frequencies and mass ratios with increase in damping ratio in the second mode of Model B

FIGURE 7 Variations in modal shapes with increase in damping ratio in second mode of Model B

FIGURE 8 Response spectra of input earthquakes to 10-DOF lumped-mass models

FIGURE 9 Peak response distributions of 10-DOF lumped-mass models 
TABLE 1 Stiffness and damping values for the three 10-DOF models

\begin{tabular}{|c|c|c|c|c|}
\hline \multirow{2}{*}{ Story } & \multicolumn{3}{|c|}{ Stiffness $k_{i}(\mathrm{kN} / \mathrm{m})$} & Damping ratio \\
\hline & Model A & Model B & Model C & \multirow{5}{*}{$\begin{array}{l}2 \% \text { in the } 2 \text { nd mode of the upper } \\
\text { substructure including isolation story. } \\
\text { Its damping sub-matrix is proportional } \\
\text { to the corresponding stiffness matrix. }\end{array}$} \\
\hline 10 & 310,870 & 388,340 & 907,120 & \\
\hline 9 & 318,720 & 397,170 & 914,960 & \\
\hline 8 & 328,520 & 406,980 & 921,830 & \\
\hline 7 & 338,330 & 416,780 & 931,630 & \\
\hline $\begin{array}{c}6 \\
\text { Isolation }\end{array}$ & \multicolumn{3}{|c|}{12,337} & $\begin{array}{l}20 \% \text { at } 0.25 \mathrm{~Hz} \\
\text { The natural frequency of the upper } \\
\text { substructure is fixed as } 0.25 \mathrm{~Hz} \text { when it } \\
\text { is assumed to be rigid. }\end{array}$ \\
\hline 5 & \multicolumn{3}{|c|}{$1,814,200$} & \multirow{5}{*}{$\begin{array}{l}\qquad 2 \% \text { at } 2.0 \mathrm{~Hz} \\
\text { The 1st natural frequency of the lower } \\
\text { substructure is fixed as } 2.0 \mathrm{~Hz} \text {. } \\
\text { Its damping sub-matrix is proportional } \\
\text { to the corresponding stiffness matrix. }\end{array}$} \\
\hline 4 & \multicolumn{3}{|c|}{$1,853,460$} & \\
\hline 3 & \multicolumn{3}{|c|}{$1,902,490$} & \\
\hline 2 & \multicolumn{3}{|c|}{$1,961,330$} & \\
\hline 1 & \multicolumn{3}{|c|}{$2,010,360$} & \\
\hline
\end{tabular}

TABLE 2 Natural frequencies and damping ratios of 10-DOF models

\begin{tabular}{ccccccc}
\hline & \multicolumn{2}{c}{ Model A } & \multicolumn{2}{c}{ Model B } & \multicolumn{2}{c}{ Model C } \\
\cline { 2 - 7 } Mode & $\begin{array}{c}\text { Frequency } \\
(\mathrm{Hz})\end{array}$ & $\begin{array}{c}\text { Damping } \\
\text { ratio } \\
(\%)\end{array}$ & $\begin{array}{c}\text { Frequency } \\
(\mathrm{Hz})\end{array}$ & $\begin{array}{c}\text { Damping } \\
\text { ratio } \\
(\%)\end{array}$ & $\begin{array}{c}\text { Frequency } \\
(\mathrm{Hz})\end{array}$ & $\begin{array}{c}\text { Damping } \\
\text { ratio } \\
(\%)\end{array}$ \\
\hline 1 & 0.242 & 17.9 & 0.243 & 18.2 & 0.245 & 18.7 \\
2 & 1.830 & 5.2 & 1.985 & 2.0 & 2.033 & 6.4 \\
3 & 1.997 & 8.0 & 2.043 & 10.7 & 2.992 & 5.1 \\
4 & 3.371 & 5.7 & 3.756 & 5.5 & 5.686 & 4.5 \\
5 & 4.636 & 5.9 & 5.167 & 5.9 & 5.754 & 7.6 \\
\hline
\end{tabular}

TABLE 3 Mass ratios corresponding to Figure 6

\begin{tabular}{|c|c|c|c|c|c|c|}
\hline \multirow{3}{*}{$\begin{array}{c}\text { Possibility in model } \\
\text { Figure } 5\end{array}$} & \multicolumn{2}{|c|}{ Model A } & \multicolumn{2}{|c|}{ Model B } & \multicolumn{2}{|c|}{ Model C } \\
\hline & 1 & 2 & 1 & 2 & 1 & 2 \\
\hline & (1) & (4) & (2) & $(5)$ & (3) & (6) \\
\hline $\begin{array}{c}\text { Lumped-mass } 3 \\
\text { (Upper substructure) }\end{array}$ & 1.67 & 1.75 & 1.63 & 1.87 & 2.03 & 1.90 \\
\hline Lumped-mass 2 (Middle) & 0.67 & 0.75 & 0.60 & 0.83 & 0.79 & 0.68 \\
\hline $\begin{array}{c}\text { Lumped-mass } 1 \\
\text { (Lower substructure) }\end{array}$ & & & & & & \\
\hline
\end{tabular}


TABLE 4 Peak displacements of isolators

\begin{tabular}{|c|c|c|c|c|}
\hline & & & & (Unit: cm) \\
\hline Input earthquake & $\begin{array}{c}\text { El Centro } \\
\text { (NS) }\end{array}$ & $\begin{array}{l}\text { Taft } \\
(\mathrm{EW})\end{array}$ & $\begin{array}{c}\text { Hachinohe } \\
\text { (NS) }\end{array}$ & $\begin{array}{c}\text { JMA Kobe } \\
(\mathrm{NS})\end{array}$ \\
\hline Model A & 22.0 & 20.9 & 23.2 & 17.2 \\
\hline Model B & 22.7 & 20.5 & 23.8 & 16.1 \\
\hline Model C & 8.7 & 10.8 & 7.8 & 6.3 \\
\hline
\end{tabular}




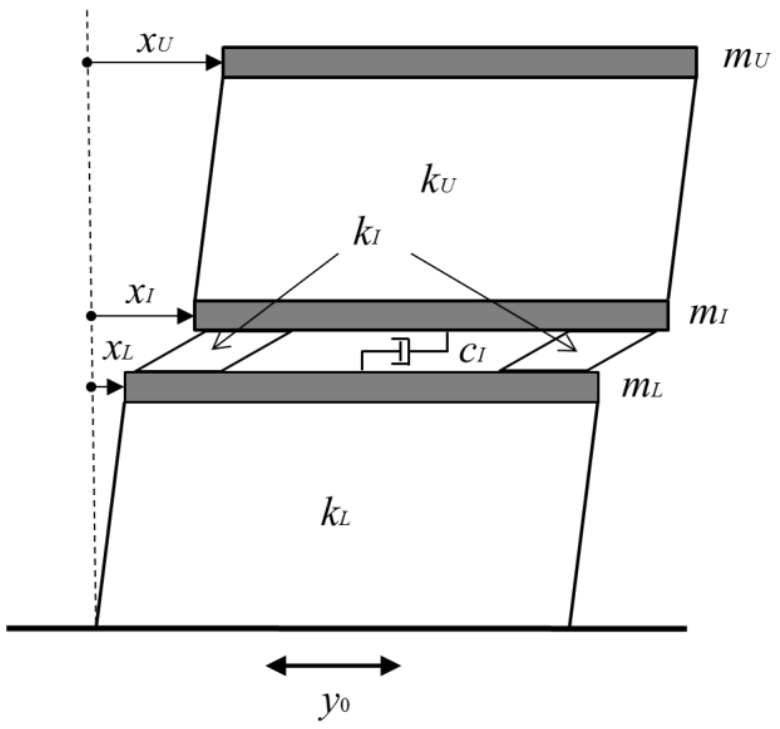

FIGURE 13 -DOF lumped-mass model for inter-story seismic isolation

Additional damping ratio

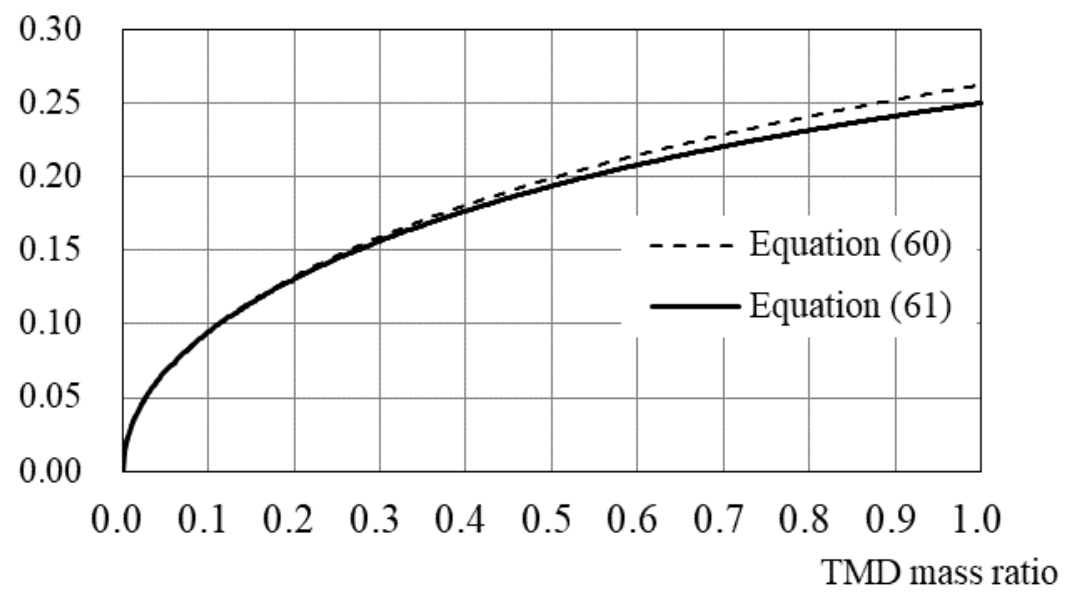

FIGURE 2 Additional damping ratios with respect to TMD mass ratio 


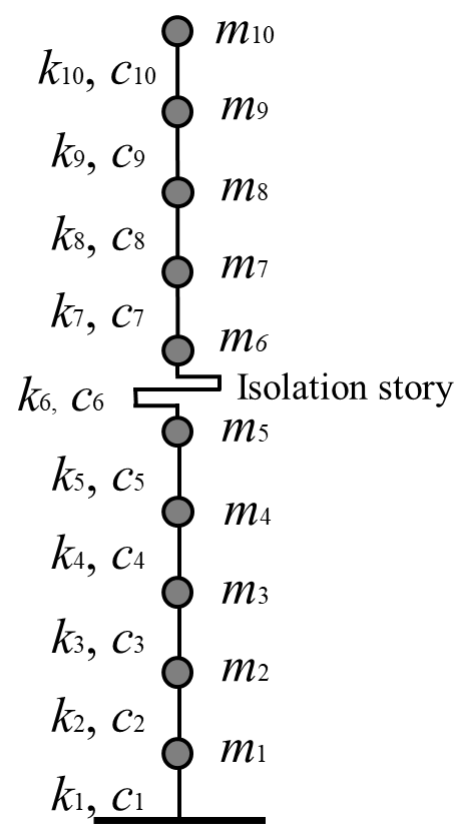

FIGURE 3 10-DOF lumped-mass model for numerical verification

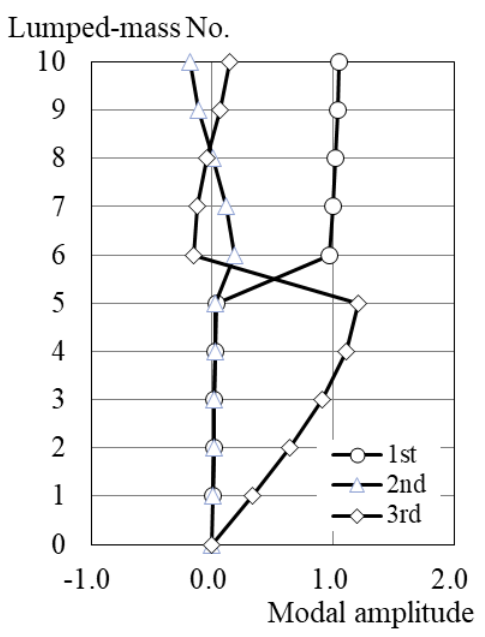

(1) Model A

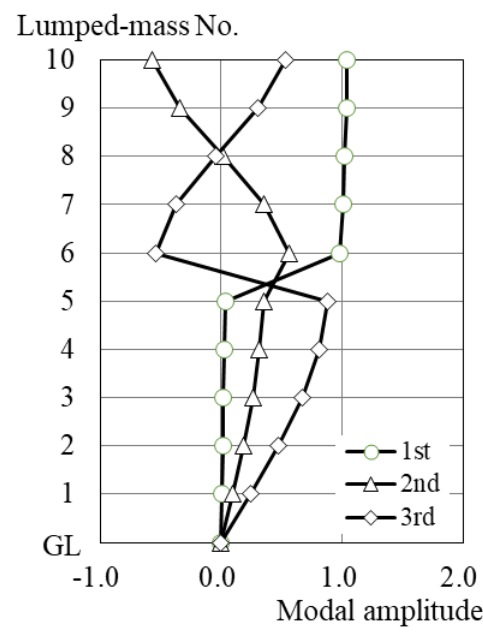

(2) Model B

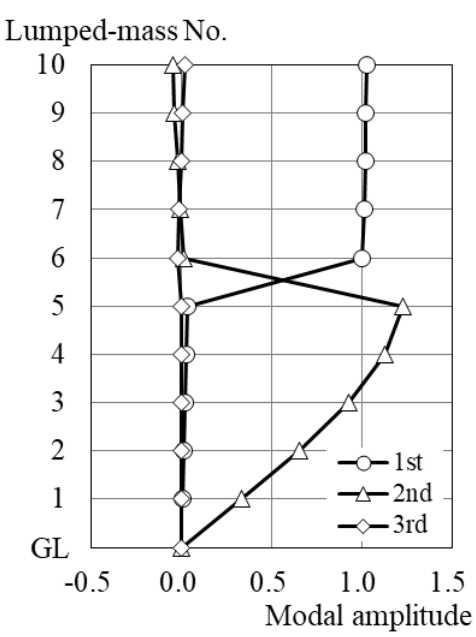

(3) Model C

FIGURE 4 Modal shapes with excitations' participation factors of 10-DOF models 


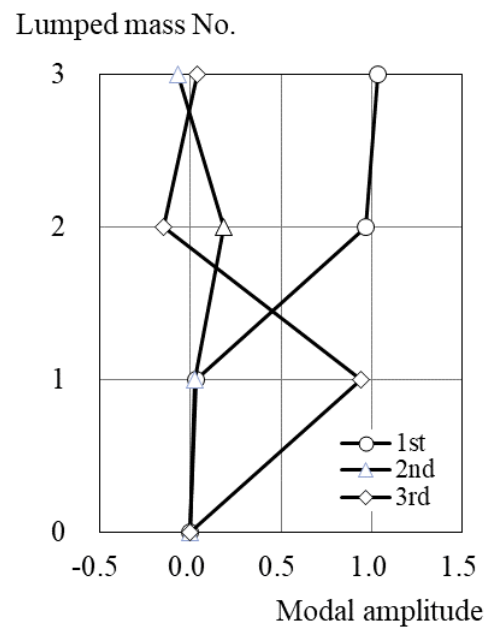

(1) Model A-1

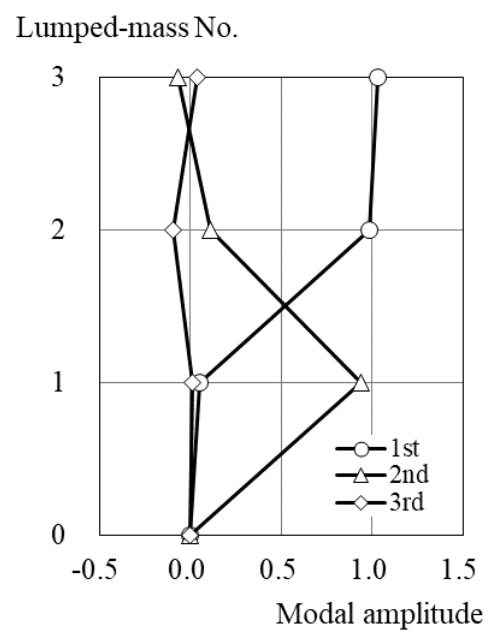

(4) Model A-2

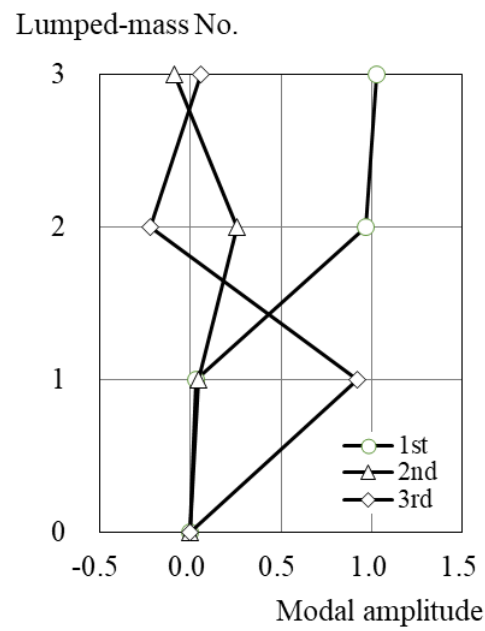

(2) Model B-1

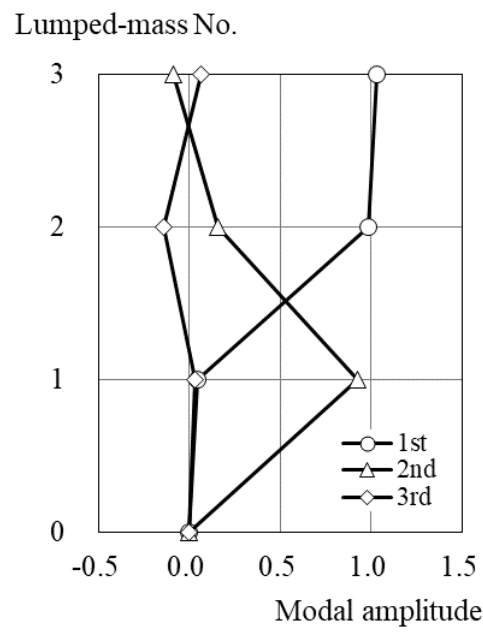

(5) Model B-2

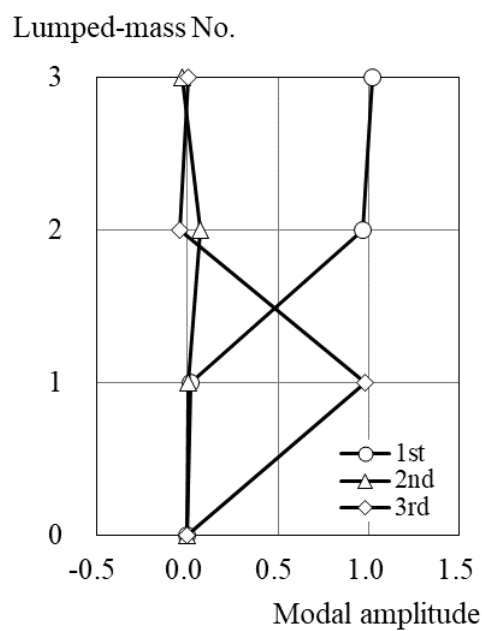

(3) Model C-1

Lumpe- mass No.

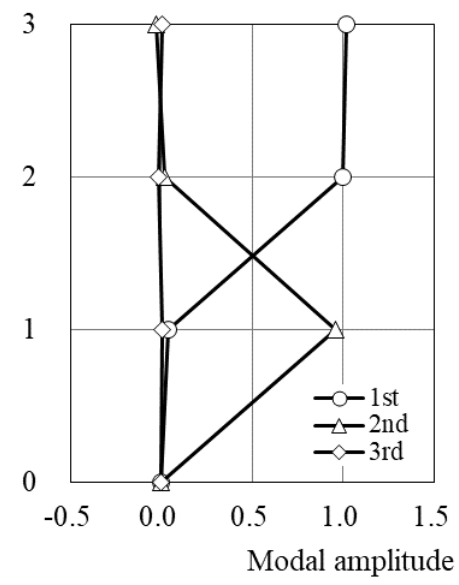

(6) Model C-2

FIGURE 5 Modal shapes with excitations' participation factors of 3-DOF models simplified from 10-DOF models 


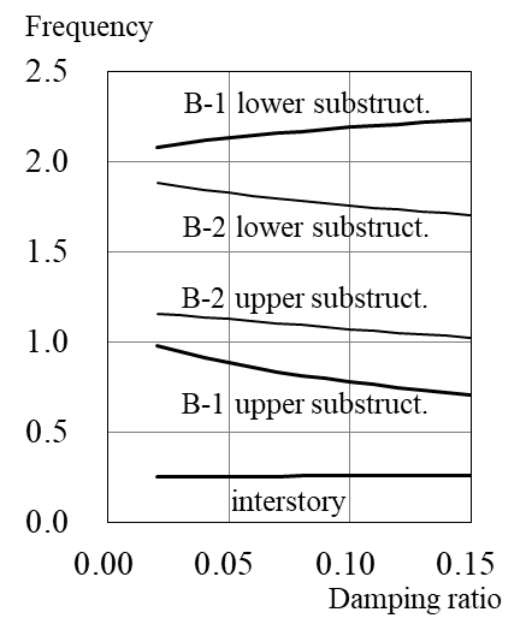

(1) Frequencies

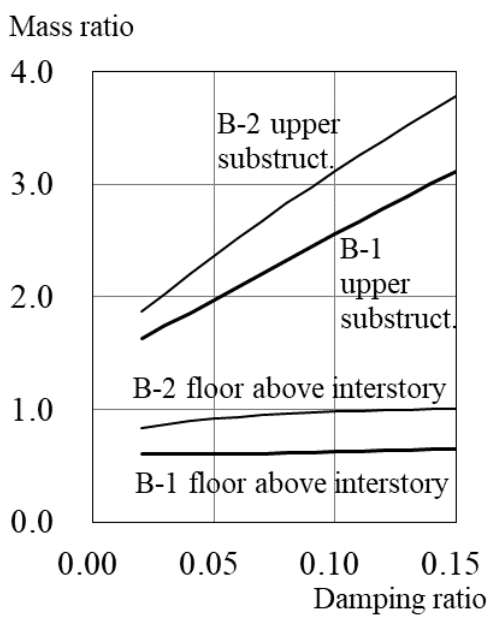

(2) Mass ratios

FIGURE 6 Variations in natural frequencies and mass ratios with increase in damping ratio in the second mode of Model B 


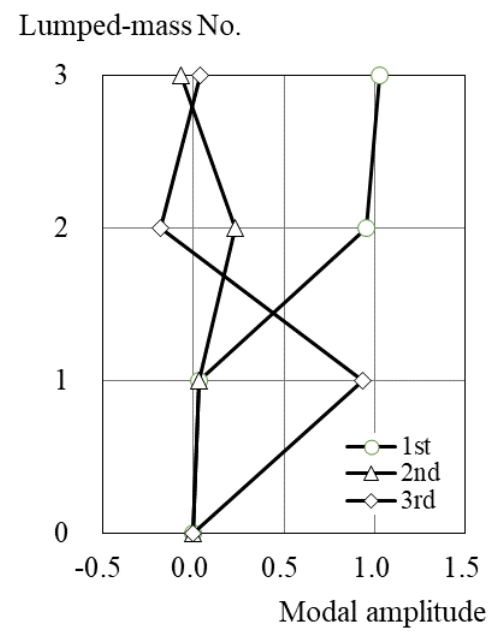

(1) Model B- $1, h_{2}=5 \%$

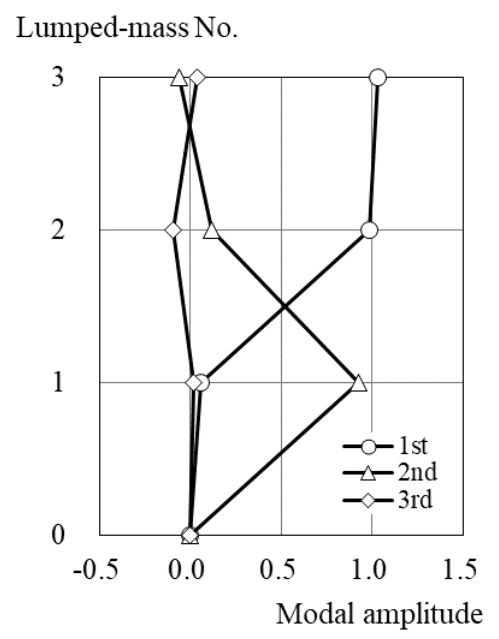

(1) Model B-2, $h_{2}=5 \%$
Lumped-mass No

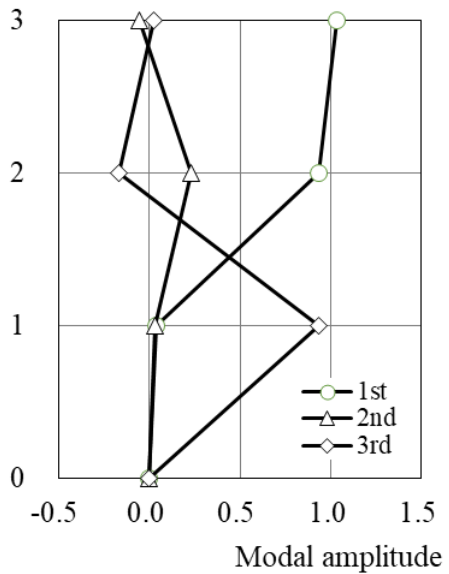

(2) Model B-1, $h_{2}=10 \%$

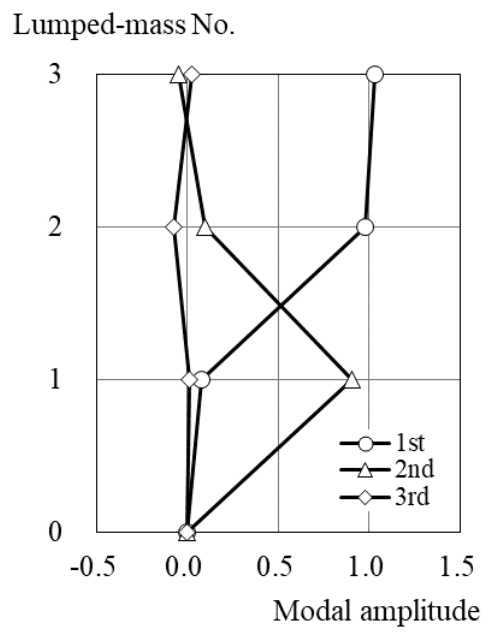

(2) Model B-2, $h_{2}=10 \%$
Lumped-mass No.

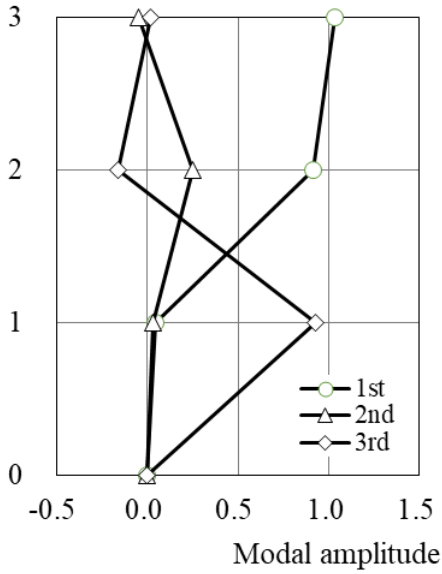

(3) Model B-1, $h_{2}=15 \%$

Lumped-mass No.

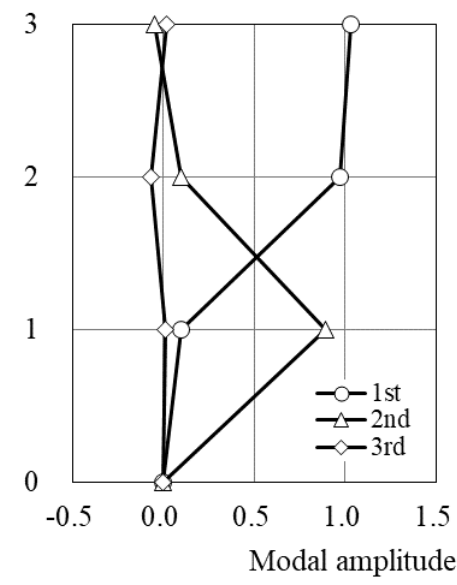

(3) Model B-2, $h_{2}=15 \%$

FIGURE 7 Variations in modal shapes with increase in damping ratio in second mode of Model B 


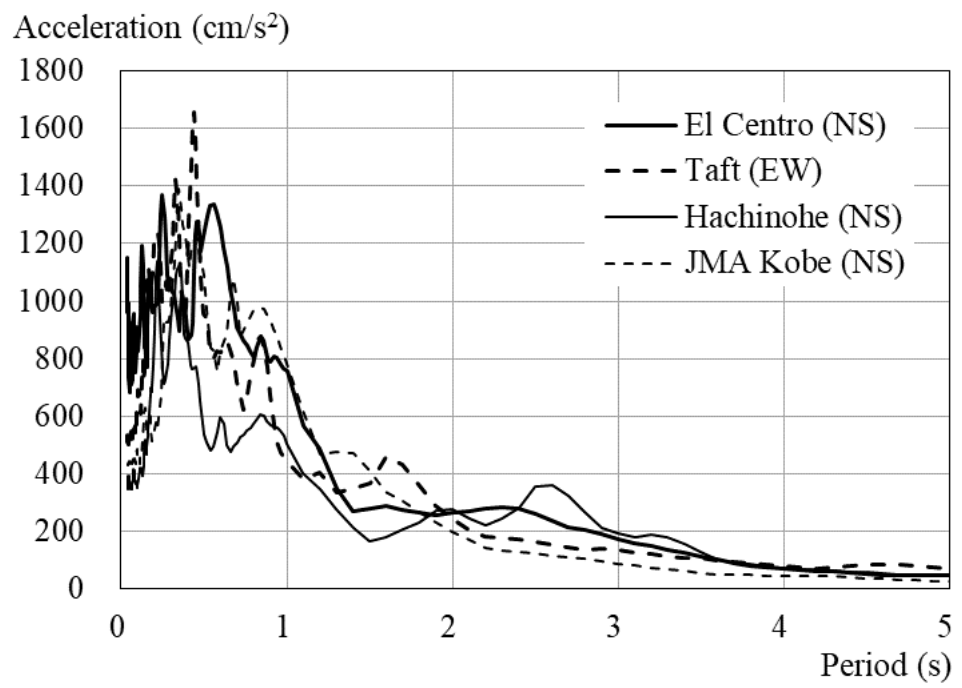

(1) Acceleration response spectra (Damping ratio 5\%)

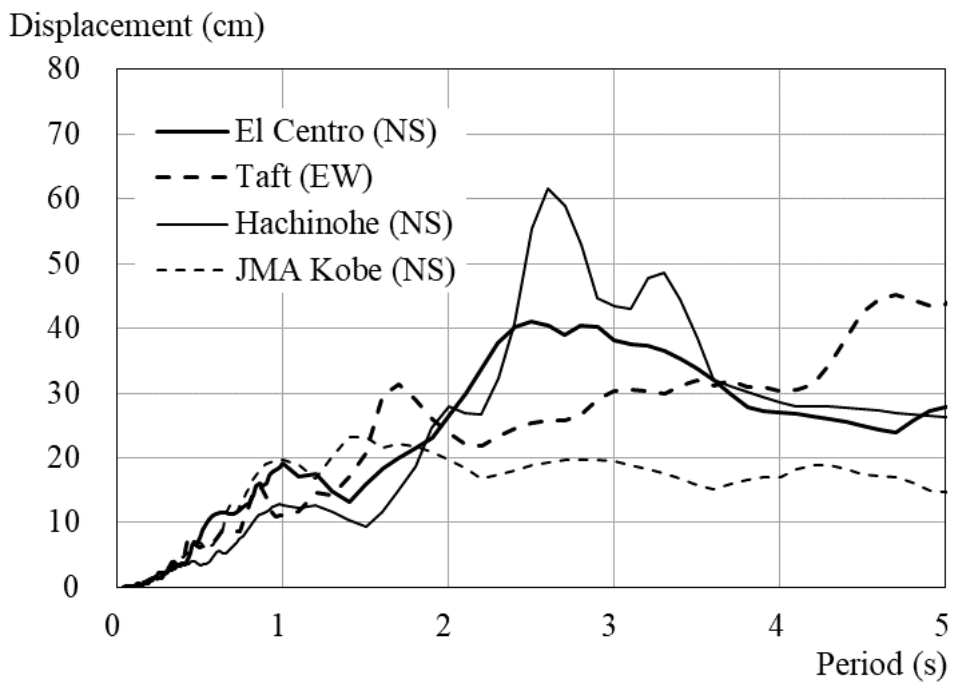

(2) Displacement response spectra (Damping ratio 5\%)

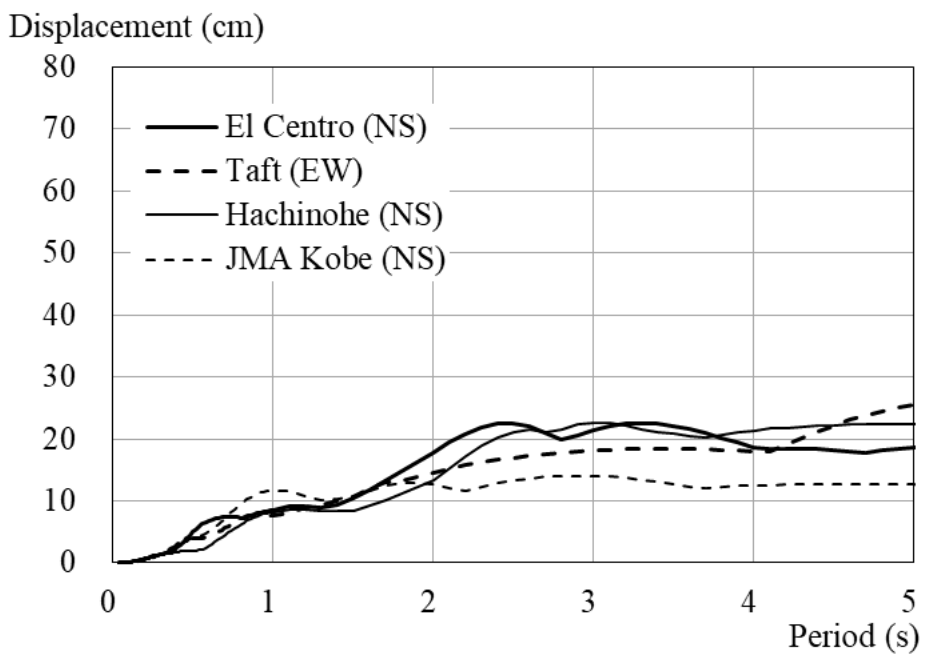

(3) Displacement response spectra (Damping ratio 20\%)

FIGURE 8 Response spectra of input earthquakes to 10-DOF lumped-mass models 


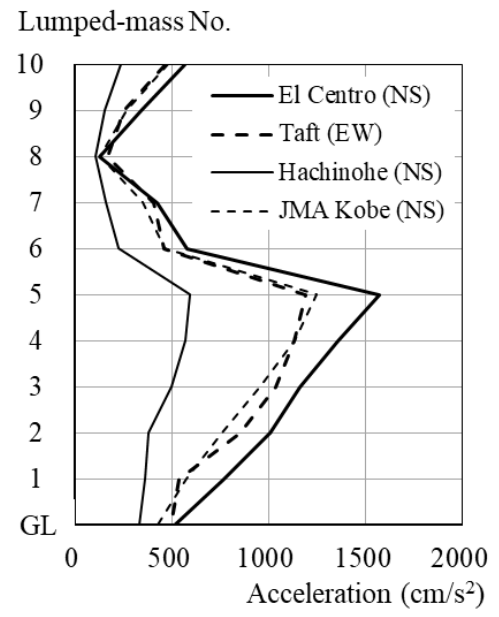

(a) Model A

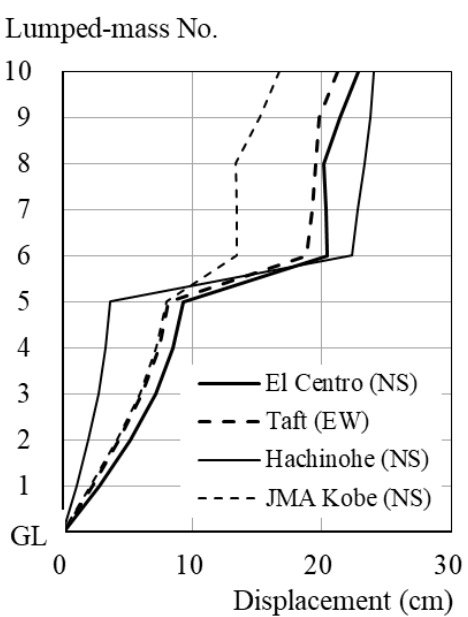

(a) Model A

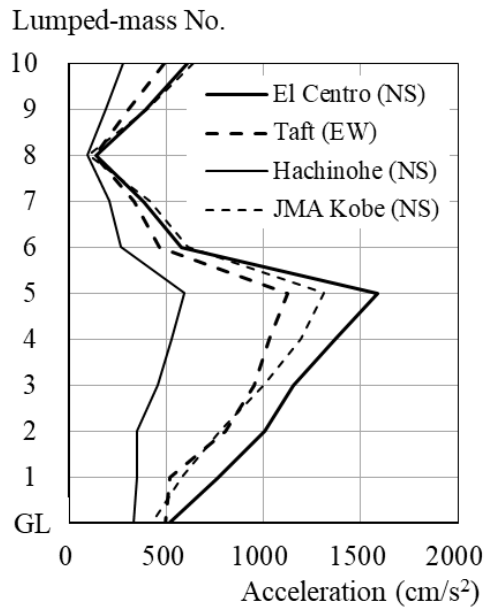

(b) Model B

(1) Accelerations

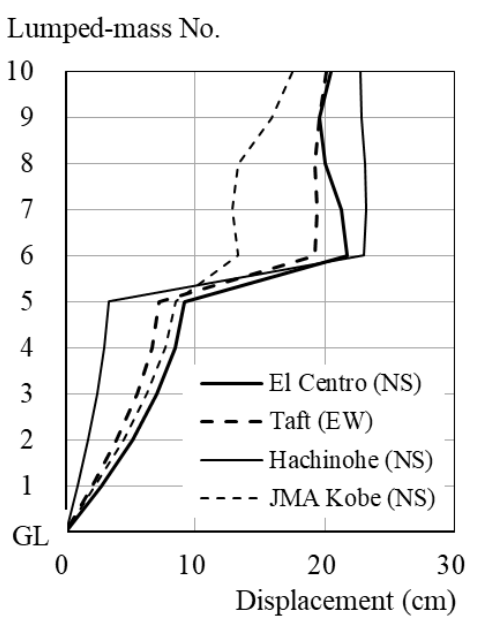

(b) Model B
Lumped-mass No.

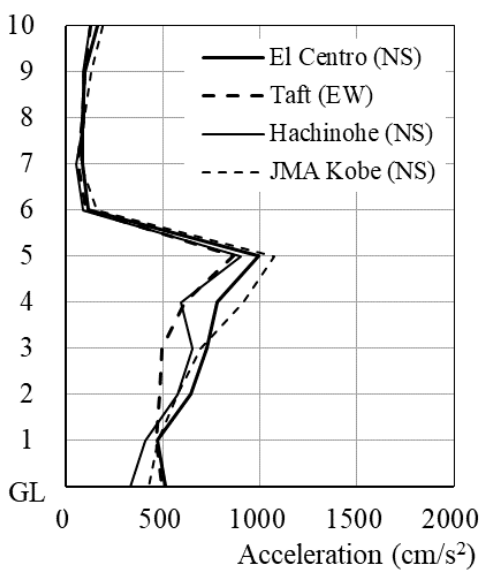

(c) Model C
Lumped-mass No.

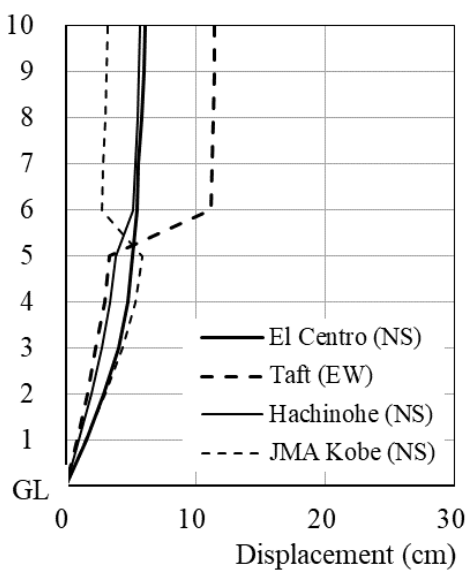

(c) Model C

(2) Displacements to the base

FIGURE 9 Peak response distributions of 10-DOF lumped-mass models 